\title{
BPM07
}

\section{New Exploration Concepts Applied to Mature \\ Areas Added Value of Sedimentary and \\ Petroleum System Modeling in West Siberia}

Y. Chenet* (Beicip-Franlab), V. Volkov (V.I. Shpilman Institute), A. Shpilman (Sib GeoProject) \& M. Saint Germes (Beicip GeoTechnologies) 


\title{
EAGE
}

\section{New exploration concepts applied to mature areas Added Value of Sedimentary and Petroleum system modeling in West Siberia}

\author{
V. Volkov (1). A. Shpilman (2), M. Saint Germes (3), PY Chenet (4)
}

(1) V.I. Shpilman Institute, Tyumen, Russia

(2) Sib GeoProject, Tyumen, Russia

(3) Beicip GeoTechnologies, Moscow, Russia

(4) Beicip Franlab, Rueil-Malmaison, France

The West Siberia Petroleum province is second to none in terms of remaining resources and oil and gas production, after Saudi Arabia. Although considered as mature for exploration, after more than 100,000 wells drilled, this province holds prospective resources, which are yet to be localized precisely.

This paper presents the application of modern techniques of paleo environment reconstruction and modeling, together with integrated application of petroleum system modeling, aiming both at identifying the reservoir distribution and quantifying oil and gas charge toward the subtle traps.

It has been successfully applied in the Jurassic sedimentary complex below the regional Bazhenov source-rock. In this complex, the sedimentary sequence interpretation shows the evolution from a system of fluviatile and coal deposits (Togur source) at the base to estuarine/coastal plain environment, further deepening to more deeper restricted marine conditions at the time of Bazhenov deposition. After Bazhenov, the basin infilling through clinoforms takes place starting from turbidite type deposits (Achimov) up to energetic fluviatile deposits (high quality reservoirs) filling up the accommodation space. Subtle stratigraphic traps can be identified in the slope deposits of the clinoforms.
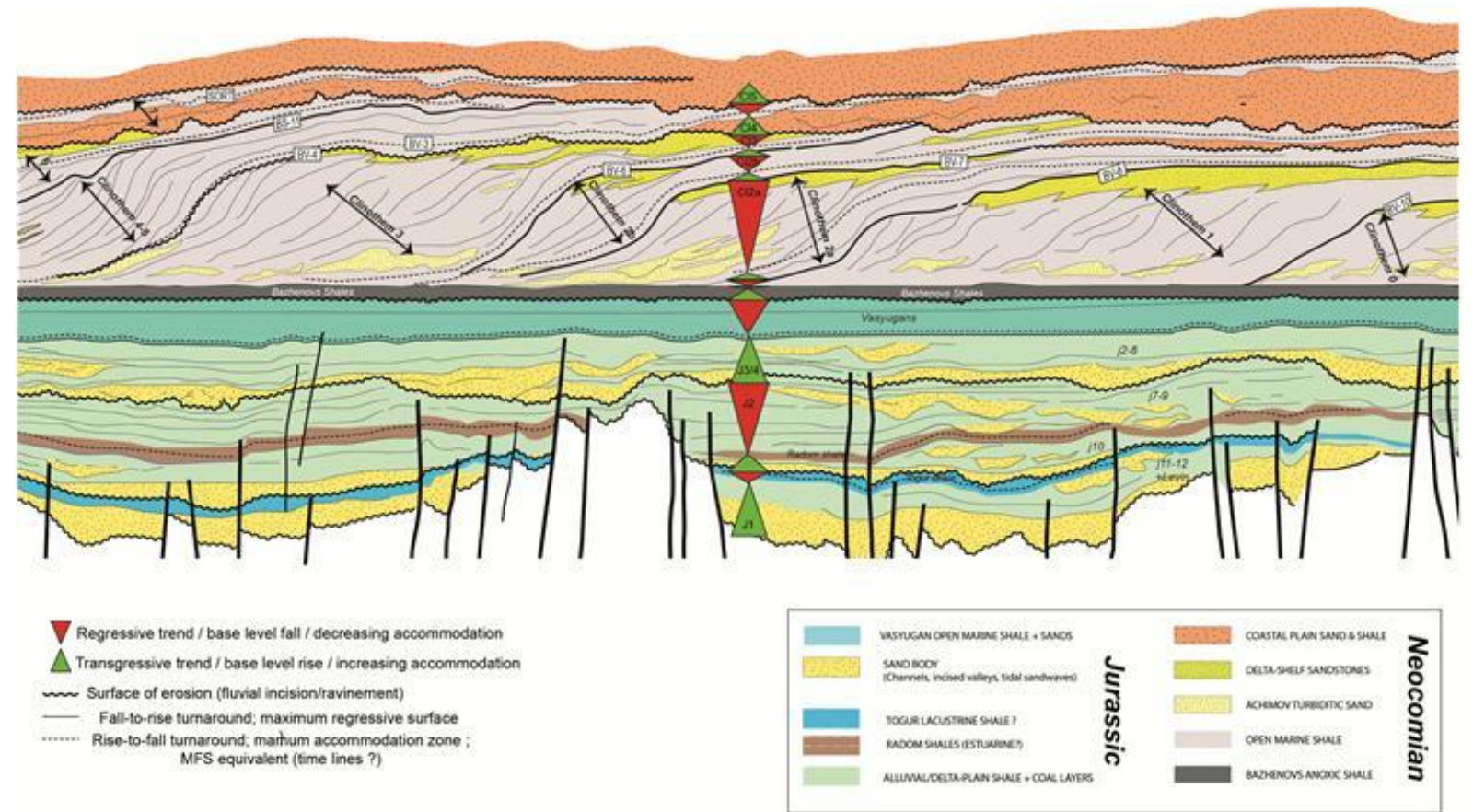

3D integrated petroleum system modeling calibrated by numerous geochemical data and masses of oil and gas in place recognized in the fields allows estimating the quantity of oil and gas charge/preservation in the various plays.

Abundant Rock Eval data allow constraining the generation and expulsion efficiency for the Bazhenov, its potential as an oil shale, and the mass balance between trapped and expelled HC. 
Morever, the detailed modeling of the $\mathrm{HC}$ charge allows to identify:

- The respective importance of capillary forces and Darcy type flow in the expulsion/migration process.

- The appropriate representation of $\mathrm{HC}$ saturation and $\mathrm{HC}$ mass distribution in the basin model, when compared to log derived $\mathrm{HC}$ saturation and accumulation data.

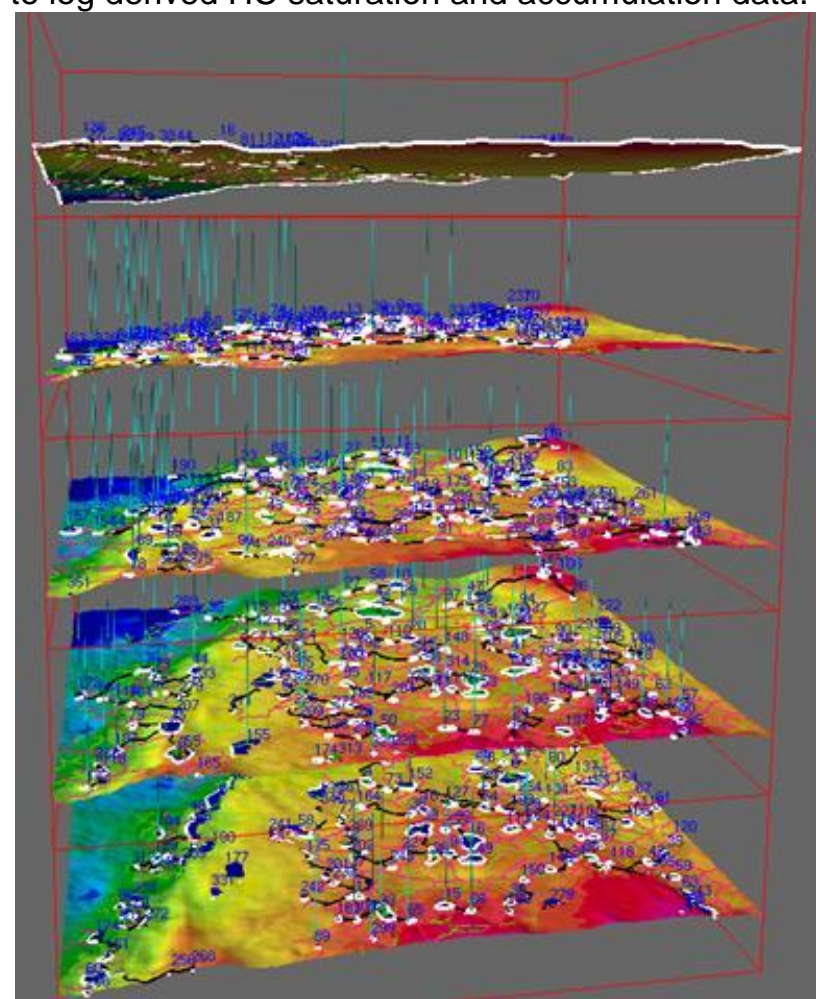

Ultimately, the basin model appears to bring an additional constraint on the prospective resource assessment and ultimate recovery, by quantifying the probability distribution of Yet to be Found HC. 